\title{
The study of 3-strand PP/PE composite monofilament Rope
}

\author{
Jian-gao Shi ${ }^{1}$, Wenwen $\mathrm{Yu}^{1}$, Yongli Liu ${ }^{1}$, Lei Wang ${ }^{1}$, Xiaoxue Chen ${ }^{1}$, Luming \\ Wang $^{1}$ and Wen-zhu Zhong ${ }^{2}$
}

${ }^{1}$ East China Sea Fisheries Research Institute, Chinese Academy of Fishery Sciences, Shanghai, China

${ }^{2}$ Fishery Machinery and Instrument Research Institute, Chinese Academy of Fishery Sciences, Shanghai, China

*jiangaoshi666@163.com

Keywords: PP/PE composite monofilament rope; tensile mechanical properties; safety

Abstract. Performance-price ratio, safety and tensile mechanical properties of the new 3-strand fishing PP/PE composite monofilament rope ("PP/PE composite monofilament rope") were studied in this paper. PP/PE composite monofilament rope was made with the fishing polypropylene/Polyethylene (PP/PE) composite monofilament using modification technology. The result shows linear density, breaking load, breaking strength and percentage of breaking elongation of PP/PE composite monofilament rope in the diameter of $8.0 \mathrm{~mm}$ are respectively $32 \mathrm{ktex}, 9.77 \mathrm{kN}, 3.05 \mathrm{cN} / \mathrm{dtex}$ and $18 \%$; if common fiber rope is replaced by PP/PE composite monofilament rope without modifying the rope, not only the rope linear, density diameter, but also the netting gear resistance and raw material consumption can be reduced; with safety and tensile mechanical properties, there is an extensive prospect of industrialized application for $\mathrm{PP} / \mathrm{PE}$ composite monofilament rope.

\section{Introduction}

PP rope and PE rope are widely used in trawl fisheries, deep water cage farming and barrier net farming, they are made of common PE monofilament and common PP monofilament in a single rope process, and their tensile mechanical properties need to be improved; as the basic structural element of a rope, the common PE monofilament and common PP monofilament are respectively made of high density PE (HDPE) and PP in the traditional spinning process ${ }^{[1-8]}$. The rope performance directly determines the expansion, complication, offshore work specialization and anti-wave safety of marine fisheries and projects(e.g. trawl, deep water cage, large floating rope barrier net, and barrier net dam for ecological marine farming, etc) ${ }^{[9-12]}$. The progress of modern fishery brings a higher demand for the performance-price ratio, safety and tensile mechanical properties of the rope, and it urgently needs to carry out the research, development and industrialized application of new rope materials ${ }^{[7-18]}$. The ultra high molecular weight polyethylene fiber rope has outstanding properties but is expensive at present, and there are only a few researches on its application and demonstration in fisheries of China, so it can not be widely generalized ${ }^{[5,9-20]}$. High performance but low price ropes are greatly demanded in the modern fisheries, so some new materials of modified fiber and reinforced fiber in a high performance-price ratio are chosen ${ }^{[1-8 \text {, }}$ ${ }^{11-12]}$. Technological progress of fiber materials (such as nano-modification and modification, etc) realizes the research, development and industrialized application of new materials for high 
performance ropes in fisheries, and has made some critical achievements ${ }^{[1-8,11-12]}$. In this paper, the test result of PP/PE composite monofilament ropes carried out in the East China Sea Fisheries Research Institute during 2012 2015 was taken as a basis to compare and analyze the performance-price ratio, safety and tensile mechanical properties between the PP/PE composite monofilament rope and the common fiber rope, expecting to provide basic data for the rope production, structural optimization and related fishery design.

\section{Experimental}

Material preparation

Preparation of fishing PP/PE composite monofilament

Screened spinning dry HDPE resin, PP resin and white oil auxiliary agent are mixed to prepare four types of PP/PE composite monofilaments (Table 1) in different PP mass percentages using modification and a special spinning process (drawing ratio 8.3 8.4), and the PP/PE composite monofilament with the highest breaking strength therein is used as the new basal fiber material for $\mathrm{PP} / \mathrm{PE}$ composite monofilament rope, i.e. the fishing PP/PE composite monofilament.

Table 1 Impact of PP mass percentage on the mechanical properties of PP/PE composite monofilament

\begin{tabular}{|c|c|c|c|c|c|c|}
\hline SN & $\begin{array}{c}\text { PP mass } \\
\text { percentage } \\
(\%)\end{array}$ & $\begin{array}{c}\text { Linear } \\
\text { density } \\
(\mathbf{d t e x})\end{array}$ & $\begin{array}{c}\text { Breaking } \\
\text { strength } \\
\text { (cN/dtex) }\end{array}$ & $\begin{array}{c}\text { Knot } \\
\text { breaking } \\
\text { strength } \\
\text { (cN/dtex) }\end{array}$ & $\begin{array}{c}\text { Percentage of } \\
\text { breaking } \\
\text { elongation } \\
(\%)\end{array}$ & $\begin{array}{c}\text { Drawing } \\
\text { ratio }\end{array}$ \\
\hline 1 & $41 \sim 43$ & 4.25 & 6.13 & 5.98 & 15.0 & 8.4 \\
\hline 2 & $80 \sim 84$ & 4.24 & 6.54 & 6.33 & 12.5 & 8.4 \\
\hline 3 & $120 \sim 124$ & 4.03 & 6.47 & 5.38 & 12.0 & 8.3 \\
\hline 4 & $398 \sim 402$ & 5.06 & 5.64 & 4.78 & 11.8 & 8.3 \\
\hline
\end{tabular}

Preparation of PP/PE composite monofilament rope

The PP/PE composite monofilament rope in a diameter of $8.0 \mathrm{~mm}$ is made of the basal fiber of fishing PP/PE composite monofilament via ring twisting, strand combining, and rope making, checking and post-treating. The common 3-strand polyamide (PA) rope, common 3-strand PE rope an 4-strand twisted PE rope are made of the common synthesized fiber as per the indexes for the standard acceptable product ${ }^{[1-2,12,21]}$.

Testing method

Test instruments cover an electronic balance FA2004N, an electronic scale ACS-15A from China, a strength tester INSTRON-4466 (range $10 \mathrm{kN}$, resolution $0.1 \mathrm{~N}$ ) from Britain and a strength tester RHZ-1600 (range $1600 \mathrm{kN}$, resolution $0.08 \mathrm{kN}$ ) from Germany.

The test was carried out in a standard lab at $(20 \pm 3)^{\circ} \mathrm{C}$ and $\mathrm{RH}(65 \pm 5) \%$ constantly, and samples were balanced in the lab for $24 \mathrm{~h}$ above. The tensile mechanical properties of PP/PE composite monofilament were tested by the strength tester INSTRON-4466 at a drawing speed of 300mm/min and a sample length of $750 \mathrm{~mm}$. The tensile mechanical properties of PP/PE composite monofilament rope were tested by the strength tester RHZ-1600 at a drawing speed of $270 \mathrm{~mm} / \mathrm{min}$. The tensile mechanical properties of PP/PE composite monofilament were tested according to SC/T $5005^{[22]}$. The tensile mechanical properties of PP/PE composite monofilament rope were tested according to GB/T $8834^{[23]}$. Valid data obtained in the test were managed according to data processing specification of the corresponding standard ${ }^{[21-23]}$. 


\section{Results and analysis}

Analysis for tensile mechanical properties of fishing PP/PE composite monofilament

Table 1 shows the tensile mechanical properties of four types of PP/PE composite monofilament in different PP mass percentages. According to Table 1, the PP/PE resin mixture with a PP mass percentage of $80 \% \sim 84 \%$ is the optimal as the PP/PE composite monofilament is given the highest breaking strength ("fishing PP/PE composite monofilament" differing from the other three types of PP/PE composite monofilament in Table 1), and it is used as the new basal fiber for making the PP/PE composite monofilament rope. The breaking strength, knot breaking strength and percentage of breaking elongation of the fishing PP/PE composite monofilament are respectively $65.4 \mathrm{cN} /$ tex, $63.3 \mathrm{cN} /$ tex and $12.5 \%$, in which, the breaking strength and knot breaking strength are improved by $25.8 \%$ and $75.8 \%$ than the fishing PE monofilament. The internal molecular orientation and structure of fishing PP/PE composite monofilament are modified by the modification, the molecular chain is gradually arranged more closely along the drawing direction with the enhanced orientation, and thus the crystallinity, orientation, breaking strength and knot breaking strength of the fishing PP/PE composite monofilament are increased ${ }^{[1-8]}$. Table 2 shows the comparison of tensile mechanical properties between the fishing PP/PE composite monofilament and common synthesized fibers.

Table 2 Comparison of tensile mechanical properties between fishing PP/PE composite monofilament and common fibers

\begin{tabular}{|c|c|c|c|}
\hline Fiber type & $\begin{array}{c}\text { Linear } \\
\text { density } \\
(\text { dtex })\end{array}$ & $\begin{array}{c}\text { Breaking strength } \\
(\mathrm{cN} / \mathrm{dtex})\end{array}$ & $\begin{array}{c}\text { Percentage of } \\
\text { breaking elongation } \\
(\%)\end{array}$ \\
\hline $\begin{array}{c}\text { Fishing PP/PE composite } \\
\text { monofilament }\end{array}$ & 424 & 6.54 & 12.5 \\
\hline Common PA fiber $^{* 1}$ & 230 & 5.50 & 22.0 \\
\hline Common PE monofilament $^{* 2}$ & 360 & 5.20 & 20.0 \\
\hline
\end{tabular}

The high breaking strength is an important property of the fishing PP/PE composite monofilament. Table 2 shows the fishing PP/PE composite monofilament has a distinctly superior breaking strength than common synthesized fibers and its strength is $18.9 \%$ and $25.8 \%$ higher than the common PA fiber and the common PE fiber respectively. Extensibility is a key factor in the material characteristics and the application properties, and low percentage of breaking elongation is another important property of the fishing PP/PE composite monofilament; comparing with common PE monofilament, the high molecular chain of fishing PP/PE composite monofilament has a low elongation deformation rate in drawing (being elongated or drifted), and the percentage of breaking elongation of fishing PP/PE composite monofilament is lower than common synthesized fibers ${ }^{[1-8]}$. The percentage of breaking elongation of fishing PP/PE composite monofilament is $12.5 \%, 43.2 \%$ and $37.5 \%$ lower than the common PA fiber and the common PE monofilament.

Analysis for tensile mechanical properties of fishing PP/PE composite monofilament rope

The PP/PE composite monofilament rope in a diameter of $8.0 \mathrm{~mm}$ is made of the fishing PP/PE composite monofilament, and the test result of its tensile mechanical properties and the comparison 
with common synthesized bier ropes are shown in Table 3.

Table 3 Comparison of tensile mechanical properties between PP/PE composite ropes and common synthetic fiber ropes

\begin{tabular}{|c|c|c|c|c|c|}
\hline Rope & $\begin{array}{c}\text { Diameter } \\
(\mathrm{mm})\end{array}$ & $\begin{array}{c}\text { Linear } \\
\text { density } \\
\text { (ktex) }\end{array}$ & $\begin{array}{c}\text { Breaking } \\
\text { strength } \\
(k N)\end{array}$ & $\begin{array}{l}\text { Breaking } \\
\text { strength } \\
\text { (cN/dtex) }\end{array}$ & $\begin{array}{c}\text { Percentage of } \\
\text { breaking } \\
\text { elongation } \\
(\%)\end{array}$ \\
\hline $\begin{array}{l}\mathrm{PP} / \mathrm{PE} \text { composite } \\
\text { monofilament rope }\end{array}$ & 8.0 & 32.0 & 9.77 & 3.05 & 18 \\
\hline $\begin{array}{l}\text { Acceptable product of } \\
3 \text {-strand PA rope }\end{array}$ & 8.0 & 40.0 & 9.00 & 2.25 & $55 \sim 63$ \\
\hline $\begin{array}{c}\text { Acceptable product of } \\
\text { 3-strand PE monofilament } \\
\text { rope }^{[1,21]}\end{array}$ & 8.0 & 32.7 & 5.85 & 1.79 & $45 \sim 55$ \\
\hline 4-strand twisted PE rope ${ }^{[1,24]}$ & 8.0 & 32.1 & 6.28 & 1.96 & $45 \sim 55$ \\
\hline 4-strand twisted PE rope ${ }^{[1,24]}$ & 9.0 & 40.6 & 7.92 & 1.95 & $45 \sim 55$ \\
\hline $\begin{array}{l}\text { Acceptable product of } \\
\text { 3-strand PE monofilament } \\
\text { rope } \\
{[1,21]}\end{array}$ & 10 & 49.0 & 8.85 & 1.81 & $45 \sim 55$ \\
\hline
\end{tabular}

Analysis for the breaking strength and energy saving and consumption reducing effect of PP/PE composite monofilament rope

The rope breaking strength is mainly determined by the basal fiber material, rope yarn strength load utilization rate and rope making process (e.g. rope yarn twist, rope yarn arrangement, rope length of lay and number of rope strands), etc ${ }^{[1-2,9-20]}$. Table 3 shows that the PP/PE composite monofilament rope has a superior breaking strength than common fiber ropes, and the 3-strand PA rope in a diameter of $8.0 \mathrm{~mm}$ is replaced by the PP/PE composite monofilament rope in the same diameter for the fishing rope, the rope breaking load is improved by $8.6 \%$, the linear density is reduced by $20 \%$, the raw material consumption is reduced by $20 \%$, and the fishing rope cost is cut off correspondingly; when the 3-strand PE monofilament rope in a diameter of $8.0 \mathrm{~mm}$ is replaced by the PP/PE composite monofilament rope in the same diameter for the fishing rope, the rope breaking load is improved by $67.0 \%$, the linear density is reduced by $2.1 \%$, and the raw material consumption is reduced by $2.1 \%$; when the 4 -strand twisted PE monofilament rope in a diameter of $9.0 \mathrm{~mm}$ is replaced by the PP/PE composite monofilament rope in a diameter of $8.0 \mathrm{~mm}$ for the fishing rope, the rope breaking load is improved by $23.4 \%$, the linear density is reduced by $21.2 \%$, the rope diameter is reduced by $11.1 \%$, the raw material consumption is reduced by $21.2 \%$, and the netting gear resistance in water is reduced correspondingly; when the 3-strand PE monofilament rope in a diameter of $10.0 \mathrm{~mm}$ is replaced by the $\mathrm{PP} / \mathrm{PE}$ composite monofilament rope in a diameter of $8.0 \mathrm{~mm}$ for the fishing rope, the rope breaking load is improved by $10.4 \%$, the linear density is reduced by $34.7 \%$, the rope diameter is reduced by $20 \%$, the raw material consumption is reduced by $34.7 \%$, and the netting gear resistance in water is reduced correspondingly. In all, comparing with common fiber ropes, the PP/PE composite monofilament rope has a superior breaking load with distinctly reduced consumption and resistance; in fisheries production, the 3-strand PA rope in a diameter of $8.0 \mathrm{~mm}$, the 4 -strand twisted PE rope in a diameter of $9.0 \mathrm{~mm}$, and the 3 -strand $\mathrm{PE}$ 
monofilament rope in a diameter of $10 \mathrm{~mm}$ can be replaced by the PP/PE composite monofilament rope in the same diameter to reduce the netting gear resistance in water, improve the netting gear safety, reduce the rope linear density and raw material consumption, and promote the energy saving and consumption reducing without modifying the advantage of breaking load.

Analysis for the breaking strength and breaking elongation of PP/PE composite monofilament rope

Table 3 shows that the PP/PE composite monofilament rope has higher breaking strength and lower percentage of breaking elongation than common fiber ropes. The breaking strength of PP/PE composite monofilament rope in a diameter of $8.0 \mathrm{~mm}$ is improved by $35.6 \%, 70.4 \%, 55.6 \%, 56.4 \%$ and $68.5 \%$ than the 3-strand PA rope in diameter of $8.0 \mathrm{~mm}, 3$-strand PE monofilament rope in a diameter of $8.0 \mathrm{~mm}, 4$-strand twisted PE rope in a diameter of $8.0 \mathrm{~mm}$, 4-strand twisted PE rope in a diameter of $9.0 \mathrm{~mm}$ and 3-strand PE monofilament rope in a diameter of $10 \mathrm{~mm}$ respectively; the percentage of breaking elongation is reduced by $69.5 \%, 64.0 \%, 64.0 \%, 64.0 \%$ and $64.0 \%$ than the 3 -strand PA rope in diameter of $8.0 \mathrm{~mm}$, 3-strand PE monofilament rope in a diameter of $8.0 \mathrm{~mm}$, 4-strand twisted PE rope in a diameter of $8.0 \mathrm{~mm}$, 4-strand twisted PE rope in a diameter of $9.0 \mathrm{~mm}$ and 3-strand PE monofilament rope in a diameter of $10 \mathrm{~mm}$ respectively. The distinct differences of breaking strength and elongation between the PP/PE composite monofilament rope and common fiber ropes are mainly caused by the different tensile mechanical properties of the basal fibers. The PP/PE composite monofilament rope is made of the basal fiber of fishing PP/PE composite monofilament with a breaking strength of $6.52 \mathrm{cN} / \mathrm{dtex}$ and an percentage of breaking elongation of $12.5 \%$ while the 3-strand PA rope is made of common PA fiber with a breaking strength of $5.50 \mathrm{cN} / \mathrm{dtex}$ and an percentage of breaking elongation of $22.0 \%$, the breaking strength of common PE monofilament is $5.20 \mathrm{cN} / \mathrm{dtex}$ and the breaking elongation is $20.2 \%$ (Table 2), so there is a distinct difference of tensile mechanical properties between the fishing PP/PE composite monofilament and common synthesized fibers. High breaking strength and low elongation are important features for the fishing $\mathrm{PP} / \mathrm{PE}$ composite monofilament differing from common synthesized fibers. The internal molecular structure of the fishing PP/PE composite monofilament is modified by the cross-link modifying technology, the molecular chain is arranged more closely, and the chain stretch is inhibited, so this fishing PP/PE composite monofilament in a specific aggregative structure is given a higher breaking strength and a low elongation, and the PP/PE composite monofilament rope twisted by it has a higher breaking strength and a lower elongation than common fiber ropes (Table 3) ${ }^{[1-2,9-20]}$. Comparing with the fishing PP/PE composite monofilament, the molecular interacting forces of common synthesized fibers in Table 2 are small, and the elongation strains are large, so the common fiber ropes are shaped with low breaking strengths and larger elongations (Table 3) ${ }^{[1-8]}$.

Analysis for the safety of PP/PE composite monofilament rope

Comparing with common fiber ropes (e.g. 3-strand PA rope, 3-strand PE monofilament rope and 4-strand twisted PE rope) in diameters of $8.0 \mathrm{~mm} \sim 10 \mathrm{~mm}$ in Table 3, the breaking load of PP/PE composite monofilament rope is improved by $8.6 \% \sim 67.0 \%$, and the breaking strength is improved by $35.6 \% \sim 70.4 \%$ (Table 3 ), therefore, the fishing rope breaking load and breaking strength and the fishery safety can be effectively improved by replacing the common fiber ropes in diameters of $8.0 \mathrm{~mm} \sim 10 \mathrm{~mm}$ in Table 3 with the PP/PE composite monofilament rope ${ }^{[1,10-12]}$. Similar with other high strength fiber ropes ${ }^{[1,9-20]}$, the elongation disadvantage of PP/PE composite monofilament rope is made up and the demand for impact load of fishing rope is satisfied by the high strength advantage; a greater energy can be absorbed by the PP/PE composite monofilament rope and only a little rebounding force will be generated at rope breaking, the accidental injury to fishers and 
farming farm owners caused by rope breaking can be highly reduced, and thus the fishery safety can be highly improved ${ }^{[1,9-20]}$.

\section{Conclusions}

The fishing PP/PE composite monofilament was prepared by modification, and the performance-price ratio, safety and tensile mechanical properties of the twisted PP/PE composite monofilament rope were studied in this paper. The result shows the linear density, breaking load, breaking strength and percentage of breaking elongation of PP/PE composite monofilament rope in the diameter of $8.0 \mathrm{~mm}$ are respectively $32 \mathrm{ktex}, 9.77 \mathrm{kN}, 3.05 \mathrm{cN} / \mathrm{dtex}$ and $18 \%$; if the common fiber rope is replaced by the PP/PE composite monofilament rope without modifying the rope breaking load advantage, the rope diameter can be reduced by $0 \sim 20 \%$, the linear density can be reduced by $2.1 \% \sim 34.7 \%$, the breaking strength can be enhanced by $35.6 \% \sim 68.5 \%$, the percentage of breaking elongation can be decreased by $61.7 \% \sim 69.5 \%$, the raw material consumption can be reduced by $2.1 \% \sim 34.7 \%$, and the netting gear resistance can be reduced correspondingly; safety and tensile mechanical properties are favorable, and there is an extensive prospect of industrialized application.

\section{ACKNOWLEDGEMENT}

This research was funded by the Marine Economic Innovation Special Development area Demonstration Project in Guangdong province “Deep water aquaculture industry engineering technology research and development of public service platform" (GD2013-D01-001 ), 2013 Marine Economic Innovation Demonstration Project "650t Annual Yield of Daiquzu Large Yellow Croaker in Offshore Deep Water Cages", Dongtou Science and Technology Plan "Technological Development for Ecological Marine Farming Barrier High-performance Ropes \& Nets in Bailongyu Island" ( N2014K19A ), and Taizhou Science and Technology Project "Research and Development of High Performance Ropes for Deep Water Cages" (14ny17).

\section{REFERENCES}

[1] M. Sun, J. Shi, C. Xu, et al. Fishery material and technology, China agriculture press, Beijing, 2009, PP. 1-138.

[2] Committee of Teaching Material Compiling for Workers' Skill Training, Ministry of Agriculture. Rope net-making methods and operating skills. Beijing, summary of china agricultural standards. China Press of Standards, Beijing, 1997, PP. 1-160.

[3] J. Shi, L. Wang, X. Chen, et al. Fishing Netting and Antifouling Technology, China Agriculture Press, Beijing, 2011, PP. 1-446.

[4] J. Xu. Deep water cages and barrier net aquiculture,: China Agriculture Press, Beijing, 2007, PP. 1-307.

[5] L. Wang. Experimental research and the fishery application prospect of ultrahigh fibers, Journal of Fisheries of China. 24 (2000) 480-484.

[6] K. Zhang. Polymer Physics, Chemical Industry Press, Beijing, 1981, pp. 1-213.

[7] J. Shi, Wenwen Yu, Wenzhu Zhong, et al. Tensile mechanical properties of 3-strand $\mathrm{PE} / \mathrm{SiO}_{2}$ composite fiber rope, Applied Mechanics and Materials, 1033-1034 (2014) 921-926. 
[8] J. Shi, L. Wang, X. Chen, et al. Progress in the research on new synthesized fibers for fisheries. Journal of Modern Fisheries Information, 23 (2008) 9-22.

[9] H. Ma, Y. Guo, L Mao. Research on the ultrahigh molecular weight polyethylene composite ropes for wind and wave resistant net cage, Marine Fisheries, 27 (2005) 154-158.

[10] J. Shi, Y. Liu, L. Wang, et al. Research on the physical and mechanical properties of ultrahigh strength ropes for deep water net cages, Modern Fisheries Information, 28 (2013) 127-133.

[11] J. Shi, L. Wang, X. Chen, et al. Research on the 8-strand high performance polyethylene rope, Journal of Modern Fisheries Information, 11(2010) 17-20.

[12] J. Shi, Y. Liu, H. Ma, et al. Research on the 4-strand modified PP/PE monofilament rope for fisheries, Journal of Modern Fisheries Information, 12(2010) 16-28.

[13] Anon. Special rope stronger than steel, Fishing News International, 39 (2000) 34.

[14] Anon. New polyethylene fiber suitable for deepwater mooring ropes, Offshore, 72 (2012) 90-93.

[15] Anon. Mocrowaves to dry superstrong ropes, Fishing News International, 39 (2000) 21.

[16] Anon. Adenia II tows light Dyneema trawl, Fishing News International, 33 (1994) 14.

[17] Dingzhu Wo. Composite Materials. Chemical Industry Press, Beijing, 2000, pp. 106-113.

[18] Anon, Fiber developed for long-lasting, deep-water moorings, Advances in Textiles Technology, (2012).

[19] Y. Guo, H. Ma, L. Mao. Elongation test of fiber rope for net cage, Journal of Fisheries of China, 29 (2005) 724-727.

[20] J. Shi, L. Wang. Research on the ultrahigh molecular weight polyethylene fiber rope for fisheries, Journal of Shanghai Ocean University, 12 (2003) 371-375.

[21] GB/T 18674-2002. General technical specifications for ropes for fisheries, China Press of Standards, Beijing, (2002).

[22] SC/T 5005-2014. Polyethylene Monofilament for fisheries, China Press of Standards, Beijing, (2014).

[23] GB/T 8834-2006. Ropes - Determination of certain physical and mechanical properties, China Press of Standards, Beijing, (2006).

[24] ISO 1969: 2004. Fiber ropes - Polyethylene - 3- and 4-strand ropes. Switzerland, (2004). 